
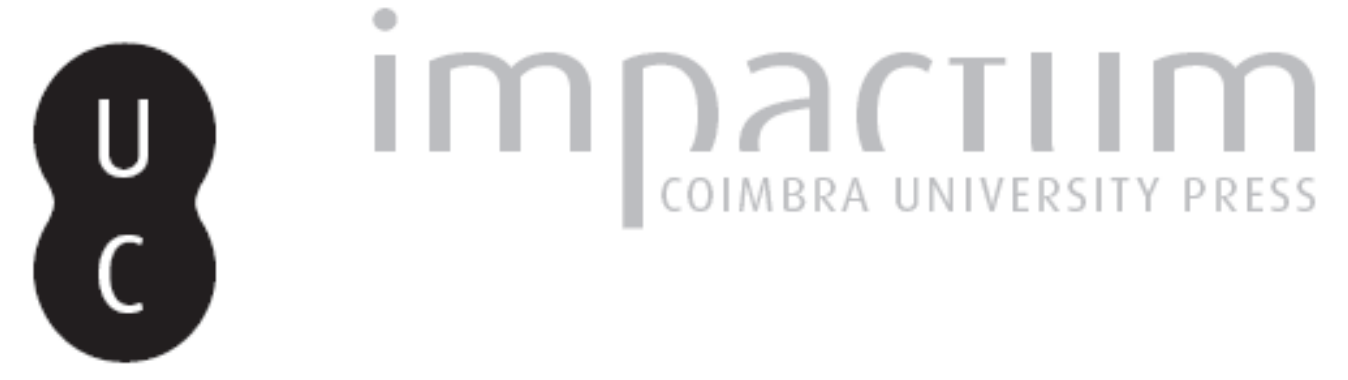

\title{
A estátua-sedente de Roriz (Barcelos) no contexto das manifestações simbólicas e rituais da Proto-História do Norte de Portugal
}

\author{
Autor(es): Bettencourt, Ana M. S.
}

Publicado por: Faculdade de Letras da Universidade de Coimbra

URL persistente:

URI:http://hdl.handle.net/10316.2/37686

DOI:

DOI:http://dx.doi.org/10.14195/1647-8657_42_4

Accessed : $\quad$ 26-Apr-2023 16:22:43

A navegação consulta e descarregamento dos títulos inseridos nas Bibliotecas Digitais UC Digitalis, UC Pombalina e UC Impactum, pressupõem a aceitação plena e sem reservas dos Termos e Condições de Uso destas Bibliotecas Digitais, disponíveis em https://digitalis.uc.pt/pt-pt/termos.

Conforme exposto nos referidos Termos e Condições de Uso, o descarregamento de títulos de acesso restrito requer uma licença válida de autorização devendo o utilizador aceder ao(s) documento(s) a partir de um endereço de IP da instituição detentora da supramencionada licença.

Ao utilizador é apenas permitido o descarregamento para uso pessoal, pelo que o emprego do(s) título(s) descarregado(s) para outro fim, designadamente comercial, carece de autorização do respetivo autor ou editor da obra.

Na medida em que todas as obras da UC Digitalis se encontram protegidas pelo Código do Direito de Autor e Direitos Conexos e demais legislação aplicável, toda a cópia, parcial ou total, deste documento, nos casos em que é legalmente admitida, deverá conter ou fazer-se acompanhar por este aviso.

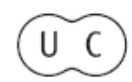


CONIMBRIGA

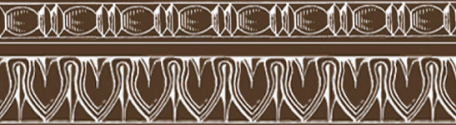

NSTITUTO DE ARQUEOLOGI

I

VOLUME XLII - 2003

A C U L D

UNIVERSIDADE DE COIMBR 
Ana M. S. Bettencourt

Professora Auxiliar do Departamento de História da Universidade do Minho.

\section{A ESTÁTUA-SEDENTE DE RORIZ (BARCELOS) NO CONTEXTO DAS MANIFESTAÇÕES SIMBÓLICAS E RITUAIS DA PROTO-HISTÓRIA DO NORTE DE PORTUGAL \\ "Conimbriga" XLII (2003) p. 141-151}

SuMÁRIO: Dá-se a conhecer uma estátua-sedente encontrada no Castro de Roriz, concelho de Barcelos, entre 1979 e 1980, hoje depositada no Museu Regional de Arqueologia D. Diogo de Sousa, em Braga.

A propósito da publicação desta peça, faz-se uma reavaliação dos achados similares detectados no Norte de Portugal e colocam-se algumas questões sobre o mundo ritual e o povoamento da Idade do Ferro, com base na análise iconográfica e dos contextos onde têm sido encontrados.

AbSTRACT: This article draws upon a "sitting statue" found at the Castro de Roriz (Barcelos) between 1979 and 1980 actually in the Museu Regional de Arqueologia D. Diogo de Sousa (Braga).

Concerning the publication of this statue we have been reappraising similar discoveries detected in the North of Portugal. We have also been putting some questions related to the ritual world and the settlement of the Iron Age based on an iconographic analysis and on the contacts stablished in the places where they have been found. 
(Página deixada propositadamente em branco) 


\section{A ESTÁTUA-SEDENTE DE RORIZ (BARCELOS) NO CONTEXTO DAS MANIFESTAÇÕES SIMBÓLICAS E RITUAIS DA PROTO-HISTÓRIA DO NORTE DE PORTUGAL}

\section{Introdução}

A peça que ora se publica foi oferecida ao Serviço Regional de Arqueologia da Zona Norte (SRAZN), em 1979 ou 1980, pelo padre Joaquim Ferreira da Silva, então pároco da freguesia de Santa Maria de Galelos, concelho de Barcelos. Posteriormente, em 1991, deu entrada no Museu Regional de Arqueologia D. Diogo de Sousa, em Braga, onde está registada com o número de inventário 0675.

Trata-se de uma figura que poderá enquadrar-se no grupo das estátuas-sedentes, cuja raridade, no contexto da Idade do Ferro ou do início da romanização do Noroeste peninsular, justifica a sua publicação. Conhecem-se, até à data, apenas quatro exemplares: um proveniente do Castro de Lanhoso (Póvoa de Lanhoso), outro da freguesia da Cividade (Braga) e dois encontrados em Xinzo de Limia (Ourense) (TEIXEIRA 1939; Ferro Couselo 1972; Silva 1986; Bettencourt \& Carvalho 1993-1994; CALO LOURIDO 1994).

\section{O contexto do achado}

Segundo informação do referido pároco, esta peça teria sido encontrada no Castro de Roriz, também conhecido por Monte do Facho, Eira dos Mouros, Cidade de Canhoane e Sanoane ${ }^{1}$. Localizado,

1 Designação referida por L. Cardoso, em 1759, nas Memórias Parochiaes, tomo 32, p. 959, citado em J. Villas-Bôas (1948: 29). 
segundo a Carta Militar de Portugal, esc. 1:25 000, f. 55, nas seguintes coordenadas Gauss: $\mathrm{M}=164,3 ; \mathrm{P}=512,2$; Altitude máx.: $320 \mathrm{~m}$, a área deste povoado abrange territórios das freguesias de Oliveira, Roriz e Santa Maria de Galegos, todas do concelho de Barcelos (Est. I e II).

Trata-se de um povoado de topo, situado num remate de esporão da serra de Roriz, em excelente posição geo-estratégica no corredor natural do Cávado fazendo, facilmente, ligação entre o litoral, a jusante, e as terras mais interiores, a montante, aliás visíveis da acrópole do povoado.

Da acrópole deste povoado há um excelente domínio visual: para este, avista-se Braga e, para oeste, o Oceano Atlântico.

As várias recolhas de superfície, os resultados da campanha de escavação, efectuada em 1978, por C. A. B. de Almeida e T. Soeiro e o reestudo deste espólio pela signatária deste trabalho (BETTENCOURT 2000b) permitiram admitir que o povoado foi ocupado desde a Idade do Bronze até à Romanização, muito provavelmente sem interrupção. À Idade do Ferro e à Romanização pertencerão os vários panos de "muralhas", as habitações circulares e rectangulares, os restos de calçada, bem como fragmentos de panelas de asa em orelha, potes, tégulas e cerâmica comum romana, detectados, sobretudo, entre a $1^{\underline{a}}$ e a $3^{\underline{a}}$ muralhas. Uma ocupação medieval também parece ter existido neste local (VeIGa 1891; VAsCONCElos 1895; AzEVEDO 1898; ForTES 1905; CoRREIA 1924; Villas-BoAs 1948; SAVORY 1951; Monteagudo 1977; Almeida et alii 1980; Costa et alii 1980; Kalb 1980; Almeida 1983; Coffyn 1985; Silva 1986; FonseCA 1987=1948; Martins 1990; BeTTENCOURT 2000b).

\section{Descrição da peça}

Bloco de granito de grão fino, de secção grosso modo losangular, polido na maioria das suas superfícies. Foi esculpido, parcialmente, na face frontal e lateral esquerda, e gravado em todas as faces (Est. III e IV).

Trata-se de uma peça de feição rudimentar, cuja combinação de diferentes técnicas permite identificar uma personagem sentada, associada a um arco e flecha, a uma planta e a um cervídeos. Dado o facto de algumas incisões terem sido avivadas posteriormente ao fabrico da peça, a contemporaneidade do cervídeos com os outros motivos não está inteiramente confirmada. 
O rosto, esculpido, é de contorno oval. Os olhos, circulares, foram avivados, talvez com uma broca, pelo que desconhecemos a sua configuração original. O nariz, algo proeminente, é ligeiramente trapezoidal e encontra-se bem definido por um sulco inciso que, na sua parte inferior, define a boca, em semicírculo. As duas orelhas são bem definidas e grandes, algo desproporcionadas em relação ao todo. Nelas está representado o buraco auditivo.

A parte esculpida do pescoço está bem modelada e termina em forma de $\mathrm{V}$, o que interpretámos como um decote. $\mathrm{O}$ braço esquerdo, apenas esboçado, sobressai atendendo ao sulco que o delimita pelo lado exterior e pela depressão, intencional, da parte interna da peça. A sua extremidade é pouco expressiva e termina com dois sulcos em forma de V, invertido, cuja relação com o braço não é clara. Este sulco foi avivado recentemente embora sem alteração da sua estrutura original. As pernas não estão alinhadas com o eixo da face, que se encontra descentrado para o lado direito, num claro aproveitamento, por parte do artesão, das saliências do bloco granítico. Foram efectuadas por duas incisões verticais, paralelas entre si, terminando cada uma delas com um pequeno sulco horizontal que interpretámos como sendo a representação dos pés.

Esta personagem estaria sentada numa cadeira de braços e espaldar, que poderão rematar em eventuais molduras de forma circular. De facto, não sabemos se estas molduras existiam, pois o que vemos, actualmente, é o resultado de círculos provocados por uma broca, à semelhança dos que se encontram no lado direito da peça e que poderão ter resultado de uma tentativa para a partir. A cadeira foi apenas gravada através de incisões profundas e encontra-se em posição excêntrica em relação ao corpo da figura. Os sulcos anteriores foram reavivados e alargados tendo esta acção provocado o lascamento superficial de parte do granito.

Do lado direito do bloco define-se um arco e uma flecha, cujos sulcos foram pouco avivados não parecendo haver alterações do desenho original. Do lado esquerdo foi insculpida uma pequena planta e, na posterior, regista-se um quadrúpede, cuja posição das pernas indicia movimento. Este animal, de pequeno porte, com uma cauda curta e representação de hastes, faz lembrar um cervídeo. Uma análise mais atenta mostra, contudo, que as incisões que definem este animal são menos profundas do que as restantes, além de terem um aspecto muito "fresco", por oposição à patine da peça. Estaremos face a uma figura desenhada posteriormente ou apenas a um reavivamento intenso que impede a visibilidade de traços anteriores? 
A profundidade dos sulcos é variável, entre $1 \mathrm{~mm}$ a $4 \mathrm{~mm}$, não tendo sido possível determinar se as diferentes profundidades se relacionam com retoques posteriores.

Todas as superfícies gravadas ou esculpidas foram polidas.

Dimensões do bloco granítico: Alt. $-24,5 \mathrm{~cm}$

Larg. máxima $-17 \mathrm{~cm}$

Espessura - $12 \mathrm{~cm}$

Apesar do carácter grosseiro e "artesanal" desta peça, a forma do rosto, do nariz, das orelhas, assim como o decote em forma de $\mathrm{V}$ encontram paralelos nas diferentes esculturas da Idade do Ferro do Norte de Portugal, razão pela qual consideramos estar perante uma peça original.

Os aspectos da sua iconografia permitem integrá-la dentro do grupo das estátuas-sedentes, sendo esta a única que se conhece portadora de cabeça.

\section{Algumas considerações}

Importa, agora, considerar os dados relativos à inserção cronológico-cultural, à funcionalidade e contexto deste achado.

Uma das questões basilares sobre estas peças consiste em determinar se seriam femininas ou masculinas.

Se considerarmos a contemporaneidade de todos os elementos, mesmo com excepção do cervídeo, somos tentados a interpretar esta figura como pertencente ao sexo masculino, pela sua associação com o arco e a flecha, cuja simbologia nos remete para exercícios ligados à caça ou à guerra ${ }^{2}$. É curioso verificar que a estátua sedente de Braga, masculina, também se associa a um elemento animal, o cavalo, atributo frequentemente relacionado com a guerra e a caça (BETTENCOURT \& CARVALHO 1993-1994). Estamos, assim, perante mais um dado que começa a dar corpo à hipótese lançada por F. Calo Lourido (1994: 697-699) de que estas peças seriam masculinas. Da mesma forma, estes argumentos permitem questionar as hipóteses de que elas representariam deusas-mães ou

2 É curioso verificar que, na arte rupestre do Vale da Casa, Nordeste de Portugal, atribuível à Idade do Ferro por A. M. Baptista (1986), são frequentes representações antropomórficas associadas a armas e à caça. 
qualquer outra representação feminina defendidas por Rodríguez Colmenero (1977) ${ }^{3}$ e Armando Coelho Ferreira da Silva (1986: 298).

Quanto à cronologia, estas estátuas têm sido integradas, pela maioria dos investigadores, na Idade do Ferro no que denominam de "plástica castreja", embora Acuña Castroviejo (1983) as insira na "plástica romana provincial da Galiza”. Como já referenciámos atrás a peça agora publicada foi detectada no Castro de Roriz (Barcelos), um povoado com ocupações da Idade do Ferro e da Romanização. É curioso verificar que a estátua sedente do Castro de Lanhoso (Póvoa de Lanhoso), igualmente de feição rudimentar, também ocorreu num povoado com cronologia desde a Idade do Ferro à Romanização, na vertente este, a "cerca de $50 \mathrm{~m}$ distante dos primeiros restos de casas..." (TEIXEIRA 1939: 125). O exemplar encontrado em Braga, descontextualizado, foi considerado como proveniente de "um dos oppida que circundavam a cidade..." (BETTENCOURT \& CARVAlHO 1993-1994: 283) dada a circunstância de não ser possível assegurar a existência de um povoado fortificado anterior à fundação de Bracara Augusta (MARTins 1990: 219). Recentemente, as obras para o novo estádio de futebol de Braga, entre outras, vieram pôr a descoberto novos e importantes dados sobre o Castro Máximo. Este povoado, a cerca de $1500 \mathrm{~m}$ para nor-noroeste do local onde ocorreu o achado da estátua-sedente de Braga foi um oppidum, de grandes dimensões, com ocupações do Ferro Inicial, do Ferro Recente e apenas do início da Romanização. Neste contexto, é muito provável que esta estátua sedente se possa relacionar com este local, cujas populações, em fase de romanização, teriam beneficiado, em termos tecnológicos, entre outros, da presença romana em Bracara Augusta. Tal teria permitido a materialização deste "ideograma" com um elevado grau de plasticidade. Quanto às estátuassedentes de Xinzo de Limia (Ourense), encontradas em mau estado e no muro de um recinto romano, consideramo-las reaproveitadas, como aliás muitos outros autores, e, possivelmente, oriundas de um dos muitos povoados da Idade do Ferro da região (Bettencourt \& CARVAlHo 1993-1994: 283).

Assim sendo, mesmo que o "modo de fazer", a tecnologia possam ser atributos de época romana, parece indiscutível que estas peças representam personagens de excepção no quadro de uma ideologia e iconografia da Idade do Ferro.

\footnotetext{
3 Em F. Calo Lourido (1994: 695).
} 
Aceitando que a estátua-sedente de Braga fosse proveniente do Castro Máximo, estaríamos face a uma situação curiosa em termos da distribuição destes achados na bacia do vale do Cávado.

As três peças provenientes desta bacia seriam todas oriundas de povoados com excelentes situações geo-estratégicas. Todos eles, Roriz (Barcelos), Castro Máximo (Braga) e Castro de Lanhoso (Póvoa de Lanhoso), de grande envergadura, com ampla diacronia de ocupação, estão localizados em situação de portela, entre o corredor natural do Cávado, pequenas vias associadas a afluentes deste rio e importantes vias de cumeada. Curiosamente, estes três povoados são equidistantes entre si, distando uns dos outros, cerca de 11/12 Km (Est. I). São recintos monumentais, com alguns panos de muralhas e portadores de espólio de excepção em termos artefactuais e escultóricos, inseríveis no Ferro Recente ou na Romanização. Do Castro de Lanhoso é proveniente um importante capacete de bronze, dois torques e um bracelete de ouro (TEIXEIRA 1939). Dada a intensa destruição a que foi votado o Castro Máximo, o conhecimento das suas características é, ainda, muito parcelar. Mesmo assim, a sua amplitude espacial já no Ferro Inicial indicia um grau de desenvolvimento distinto de muitos dos povoados coetâneos da região. Do mesmo modo que parece possível associar a estátua-sedente a esta estação, o mesmo se poderá admitir em relação à cabeça do guerreiro que a acompanhava e ao recém-descoberto "balneário", da Estação de Caminhos-de-Ferro de Braga, detectado na freguesia de Maximinos, na vertente sudoeste deste povoado.

Em relação a Roriz, podemos salientar, também, a existência de outras expressões rituais de excepção no quadro do povoamento do vale do Cávado. Referimo-nos à cabeça de guerreiro, em granito, encontrada em 1974 (ALMEIDA 1983: 81-90), aos quatro afloramentos com gravuras rupestres abstractas ${ }^{4}$ que, mesmo podendo ser anteriores, não foram destruídas durante o tempo de vida do povoado (BETTENCOURT 1999; 2000a; 2000b) e, eventualmente, ao "balneário" de Santa Maria de Galelos, localizado na vertente sudoeste do Castro de Roriz e que deverá articular-se com ele (SILVA 1986: 56-57). Que significado terão tais similitudes em termos de uma escala média de análise?

Abstraindo da visão tradicional de que os povoados da Idade do Ferro são espaços domésticos onde inscrevemos uma série de acções

4 Estes apresentam covinhas alinhadas, de diferentes dimensões, sulcos, por vezes ligando covinhas entre si e covinhas formando diferentes composições, por vezes círculos com apêndice (BETTENCOURT 1999, 2000b).

Conimbriga, 42 (2003) 141-151 
familiares resultantes de um raciocínio puramente funcionalista, percepcionamos uma outra dimensão a explorar, dentro de uma perspectiva que evita a mutilante divisão entre o ritual e o secular ou entre o doméstico e o não-doméstico e que concorda que o quotidiano não é meramente passivo e funcional (Hil \& CUMPERPATCH 1993). É assim que tendemos a interpretar os lugares referenciados, onde certamente residiram comunidades, como locais de "ampla significação simbólica e ritual" no contexto do povoamento da Idade do Ferro da bacia do Cávado. Estátuas-sedentes, estátuas de "guerreiros", "balneários", arte rupestre, elementos de adorno e de ostentação (torques, bracelete, capacete), constituiriam, assim, elementos iconográficos de uma vasta simbologia associada a determinada ideologia de poder.

Esta interpretação coloca-nos, naturalmente, outra questão que se relaciona com o papel social e ideológico dos muitos povoados da Idade do Ferro Recente e da Romanização onde tais elementos não aparecem, onde a petrificação é fruste e onde a sua localização no espaço não é tão proeminente ${ }^{5}$. Tal diferenciação no registo arqueológico será expressão de uma hierarquia de povoamento que parece já esboçar-se nos finais da Idade do Bronze da bacia do Cávado (Bettencourt 1999; 2000a, 2000b)? Em caso afirmativo, serão os locais de "ampla significação simbólica e ritual", verdadeiros centros de poder, aglutinadores de populações com o mesmo mapa cognitivo que se distribuem num território de identificação física e simbólica?

Neste caso como ajustar esta hipótese com as fontes literárias e epigráficas que definem o populus dos Bracari (grande unidade político-administrativa) que abarcaria, entre outras áreas, o curso inferior e médio da bacia do Cávado?

Não sabemos responder a estas questões, que pressupõem linhas de investigação e orientações teóricas específicas para a abordagem destas problemáticas.

Voltando ao assunto mais directo deste trabalho, as estátuas-sedentes de Roriz, Castro Máximo (?) e Castro de Lanhoso aparentam uma iconografia similar, apesar das particularidades (Est. VI). Todas as personagens estão sentadas em cadeiras de espaldar, peça de mobiliário que cremos de excepção. Em duas delas foi possível estabelecer uma associação indirecta com exercícios ou jogos físicos através da iconografia

5 Referimo-nos apenas a S. João de Rei (Póvoa de Lanhoso), ao Lago (Amares) e a Carapeços (Barcelos), para citar apenas os escavados na bacia do Cávado. 
do cavalo e do arco e a flecha. Estamos, pois, perante representações que transmitem uma mensagem codificada, inteligível para as comunidades que com elas convivem, permitindo, através dos elementos comuns, uma identificação ideológica dos grupos existentes nesta área da bacia do Cávado ${ }^{6}$.

Por outro lado, como devemos ler as especificidades que distinguem cada uma destas peças? Poderão elas ser identificativas de mapas cognitivos específicos de grupos mais restritos?

Este exercício de interpretação que resulta de uma perspectiva mais contextual de olhar o registo arqueológico, procura fugir, intencionalmente, às explicações de índole histórica que têm condicionado as leituras efectuadas neste âmbito na tentativa de suscitar novas formas de pensar e questionar as manifestações rituais das grupos humanos do I milénio AC.

\section{BIBLIOGRAFIA}

Alarcão, J. (2000), Sobre os cantões proto-históricos do Noroeste de Portugal, Santo Tirso Arqueológico 2/3 2 $2^{\mathrm{a}}$ série 45-50.

AlmeidA, C. A. B. \& Teresa Soeiro (1980), Sondagens nos castros de Abade de Neiva e Roriz (Barcelos, 1978), Actas do Seminário de Arqueologia, Guimarães, 29-35. Almeida, C. A. B. (1983), A cabeça do Guerreiro Galaico da Citânia de Roriz/Oliveira, Barcelos-Revista, 1 (2) 81-90.

Azevedo, P. A. (1898), Extractos Archeologicos das "Memorias Parochiaes" de 1758, Arqueólogo Português, 4 315-329.

Bettencourt, A. M. (1999), A Paisagem e o Homem na bacia do Cávado durante o II e o I milénios AC, 5 vols (Dissertação de Doutoramento apresentada à Universidade do Minho, na área de Pré-História e História Antiga — policopiada).

Bettencourt, A. M. (2000a), O vale do Cávado (Norte de Portugal) dos finais do III milénio aos meados do I milénio AC: sequências cronológico-culturais, Pré-História Recente da Península Ibérica, Porto. ADECAP, 79-93.

Bettencourt, A. M. (2000b), Estações da Idade do Bronze e Inícios da Idade do Ferro da bacia do Cávado (Norte de Portugal), Ed. Cadernos de Arqueologia - Monografias - 11, Ed. da Unidade de Arqueologia da Univ. do Minho, Braga.

BetTenCourt, A. M. \& H. P. CARVAlHo (1993-1994), Estátua sedente e cabeça de guerreiro galaico da região de Braga, Cadernos de Arqueologia, 10-11, Braga, 279-291.

6 Talvez esta interpretação possa ser válida, igualmente, para a bacia do Alto Lima mas as dificuldades de contextualização das peças aí encontradas impedem-nos qualquer inferência. 
Calo Lourido, F. (1993), A cultura castrexa, Ed. A Nossa Terra, Vigo.

CAlo Lourido, F. (1994), A plástica da cultura castrexa galego-portuguesa, Ed. Fundacíon Pedro Barrié de la Maza, Corunha.

Coffyn, A. (1985), Le bronze final atlantique dans la Péninsule Ibérique, Ed. Diffusion du Boccard, Paris.

Correia, A. M. (1924), Os povos primitivos da Lusitânia. (Geografia, Arqueologia, Antropologia), Ed. A. Figueirinhas, Porto.

Costa, A.; A. Faria \& J. Carvalho (1980), Sondagens arqueológicas no concelho de Barcelos - Abade de Neiva, Faria e Roriz, Actas do Seminário de Arqueologia do Noroeste Peninsular, vol. 2 5-28.

Ferro Couselo, J. (1972), Estatuas sedentes y una columna miliaria de Xinzo de Limia, Boletim Auriense, Orense, 2 329-335.

FonseCA, T. (1948=1987), O concelho de Barcelos aquém e além-Cávado, 2 vols., Barcelos.

Fortes, J. (1905b), Museu Municipal “Azuága” (Concelho de Gaya), Portugália, 2 (1) 117-119.

HiLL, J. D. (1996), How should we understand iron age societies and hillforts? A contextual study from southern Britain, J. Hill \& C. Cumberpatch (eds.) Different Iron Ages. Studies on the Iron Age in Temperate Europe, Ed. BAR International Series 602, 45-66.

Hill, J. D. \& C. C. Cumberpatch (1993), Volviendo a pensar la Edad del Hierro, Trabajos de Prehistoria, 50, Madrid, 127-137.

Kalb, P. (1980), Zur Atlantischen Bronzezeit in Portugal, Germania, 58 25-59.

Martins, M. M. (1990), O povoamento proto-histórico e a romanização da bacia do curso médio do Cávado, Cadernos de Arqueologia-Monografias 5, Braga.

Savory, H. (1951), A Idade do Bronze Atlântico no Sudoeste da Europa, Revista de Guimarães, 61 (3-4) 337-340.

Silva, A. C. F. (1986), A cultura castreja no Noroeste de Portugal, Paços de Ferreira. TeiXeira, C. (1939), Os torques do Castro de Lanhoso, Póvoa de Lanhoso, Anais da Faculdade de Ciências do Porto, 24 (4) 245-252.

TeIXEIRA, C. (1940a), O Castro de Lanhoso e o seu espólio, I $I^{a}$ Congresso do Mundo Português, 1 517-529.

TeIXEIRA, C. (1940b), Notas arqueológicas sobre o Castro de Lanhoso, Trabalhos da Sociedade Portuguesa de Antropologia e Etnologia, 9 (1-2) 245-252.

TeIXEIRA, C. (1941), Hallazgo arqueologico notable (un casco céltico de Portugal), Ampurias, 3 138-139.

VAsconcelos, J. L. (1895), Collecção Ethnographica do Sro M. d'Azuaga, O Archeólogo Portuguez, 1 20-28.

VeIgA, S. (1891), Antiguidades monumentaes do Algarve, Ed. Imprensa Nacional, vol. 4, Lisboa.

Villas-Boas, J. S. (1948), Uma nova machadinha "castreja", Boletim do Grupo de Alcaides de Faria, 1 29-32. 
EST. I

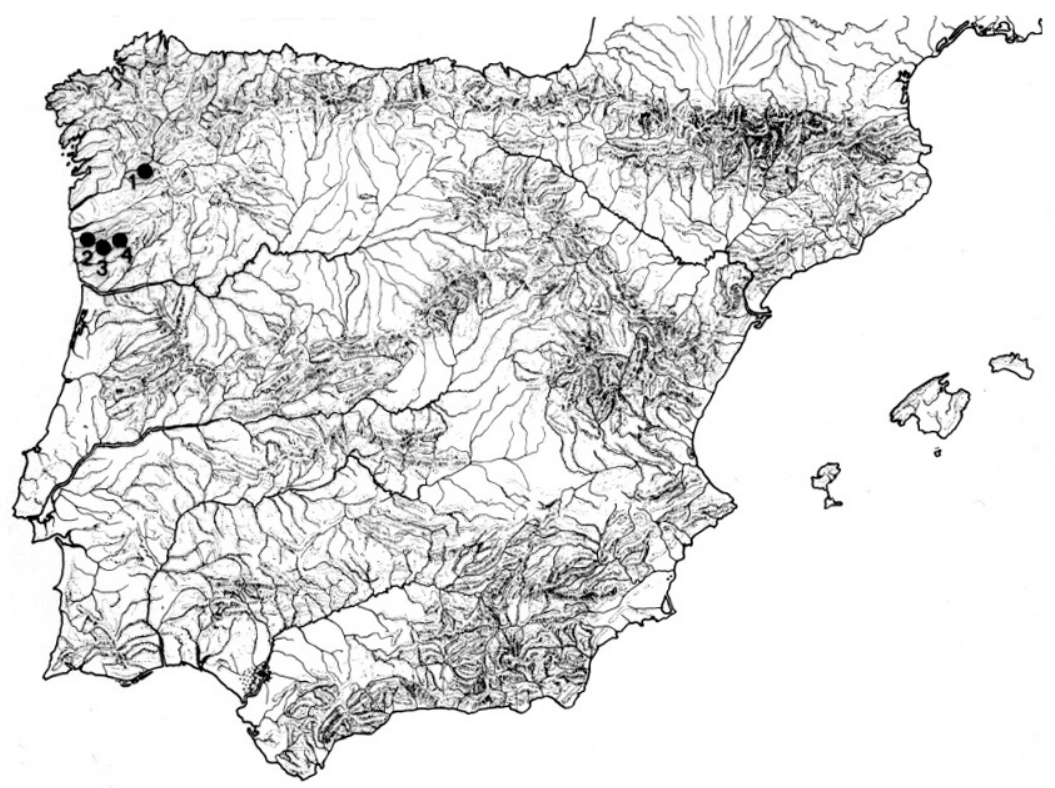

Localização dos achados referenciados na Península Ibérica: 1 - Xinzo de Limia (Ourense); 2 - Castro de Roriz (Barcelos); 3 - Braga; 4 - Castro de Lanhoso (Póvoa de Lanhoso) 

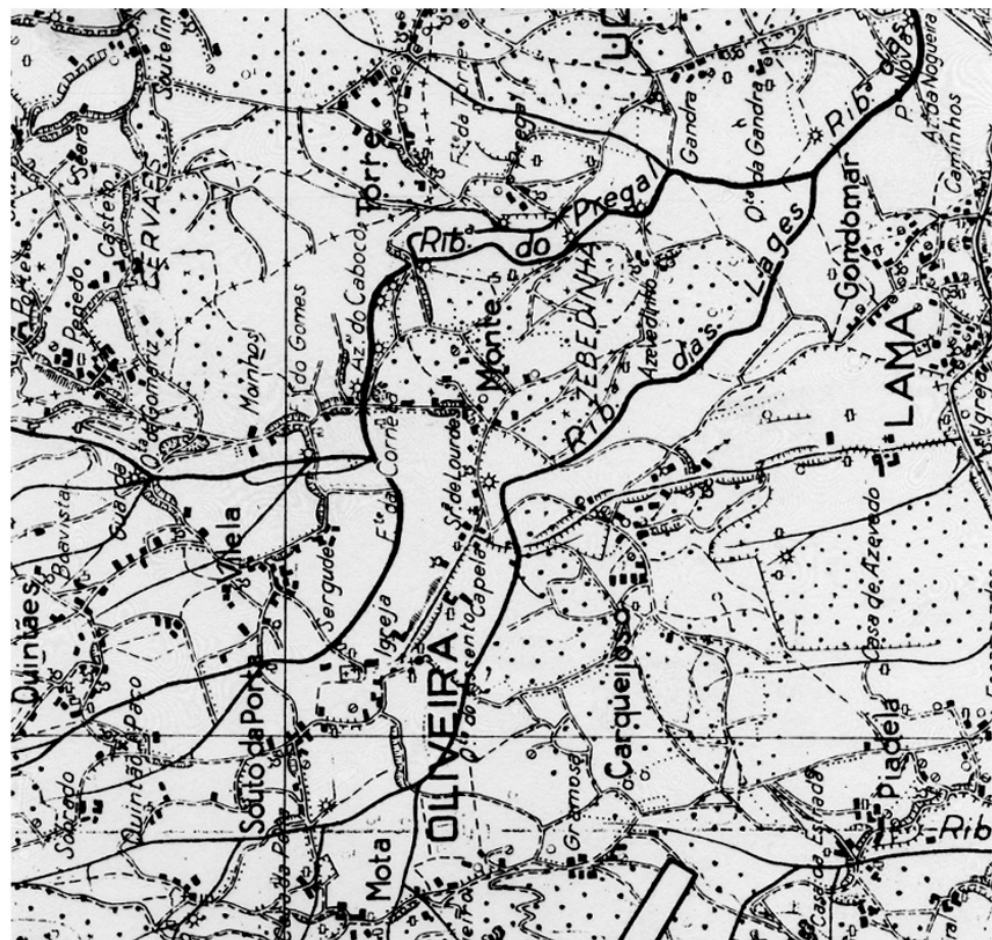

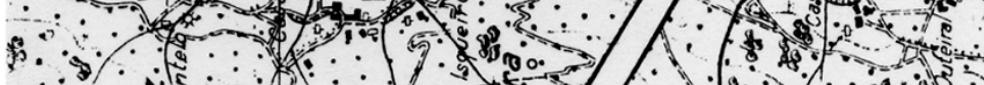

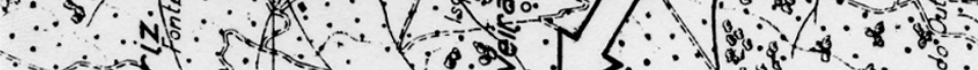

$\therefore$ क क मf : 40.

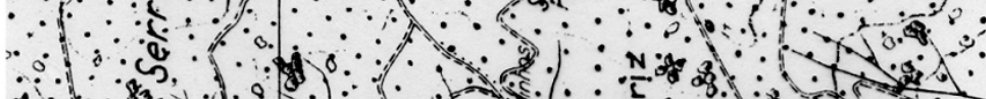
of

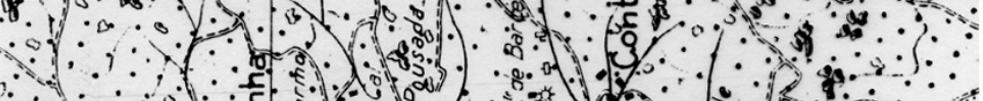

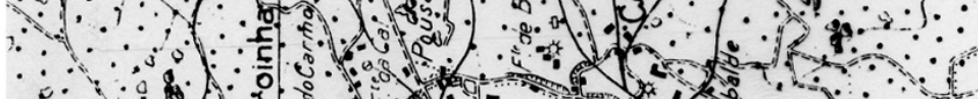

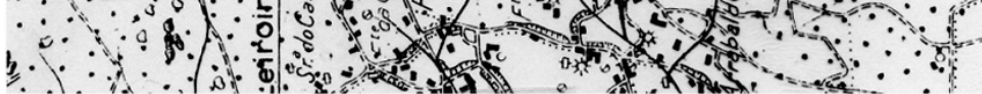


EsT. III

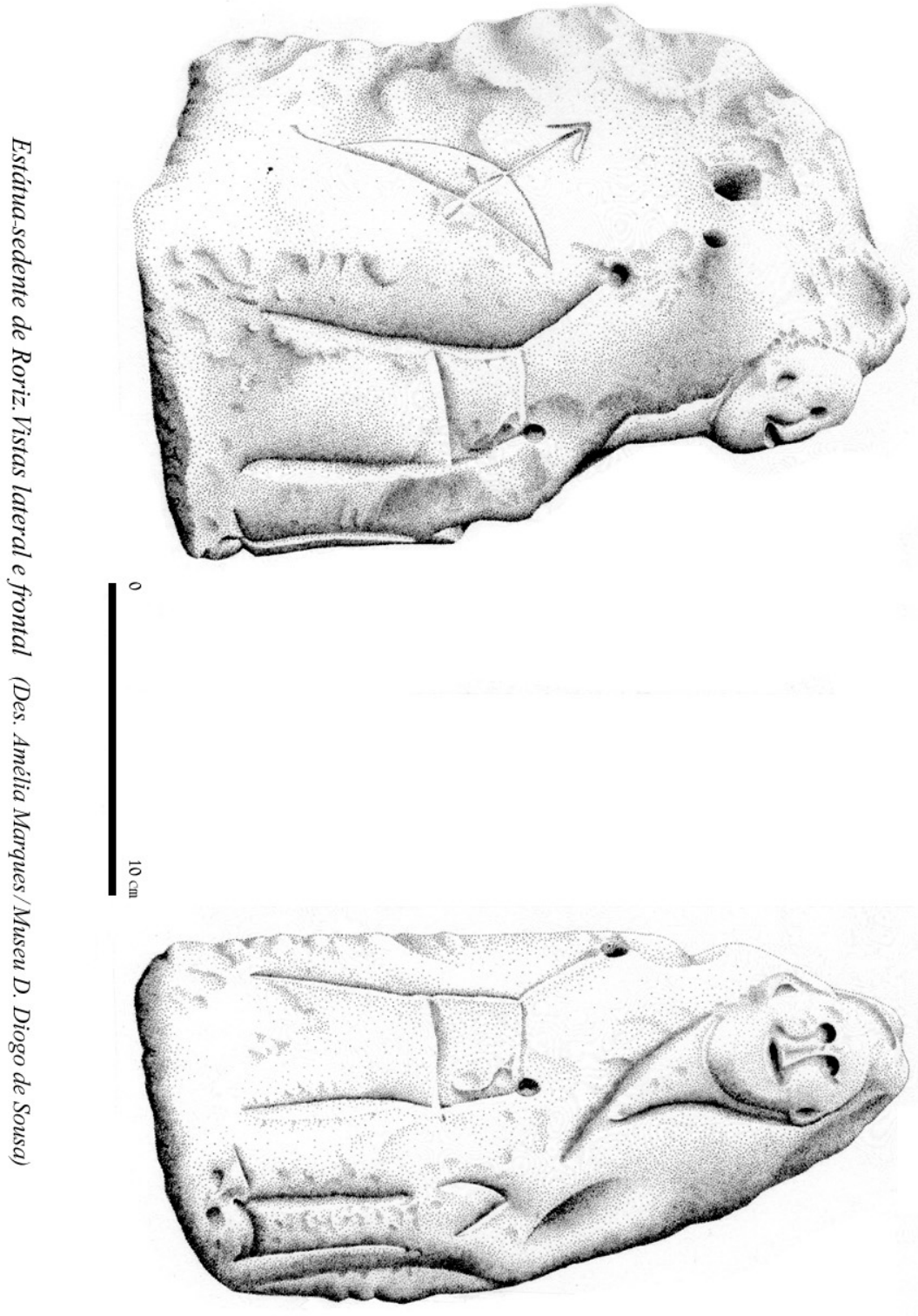


EST. IV
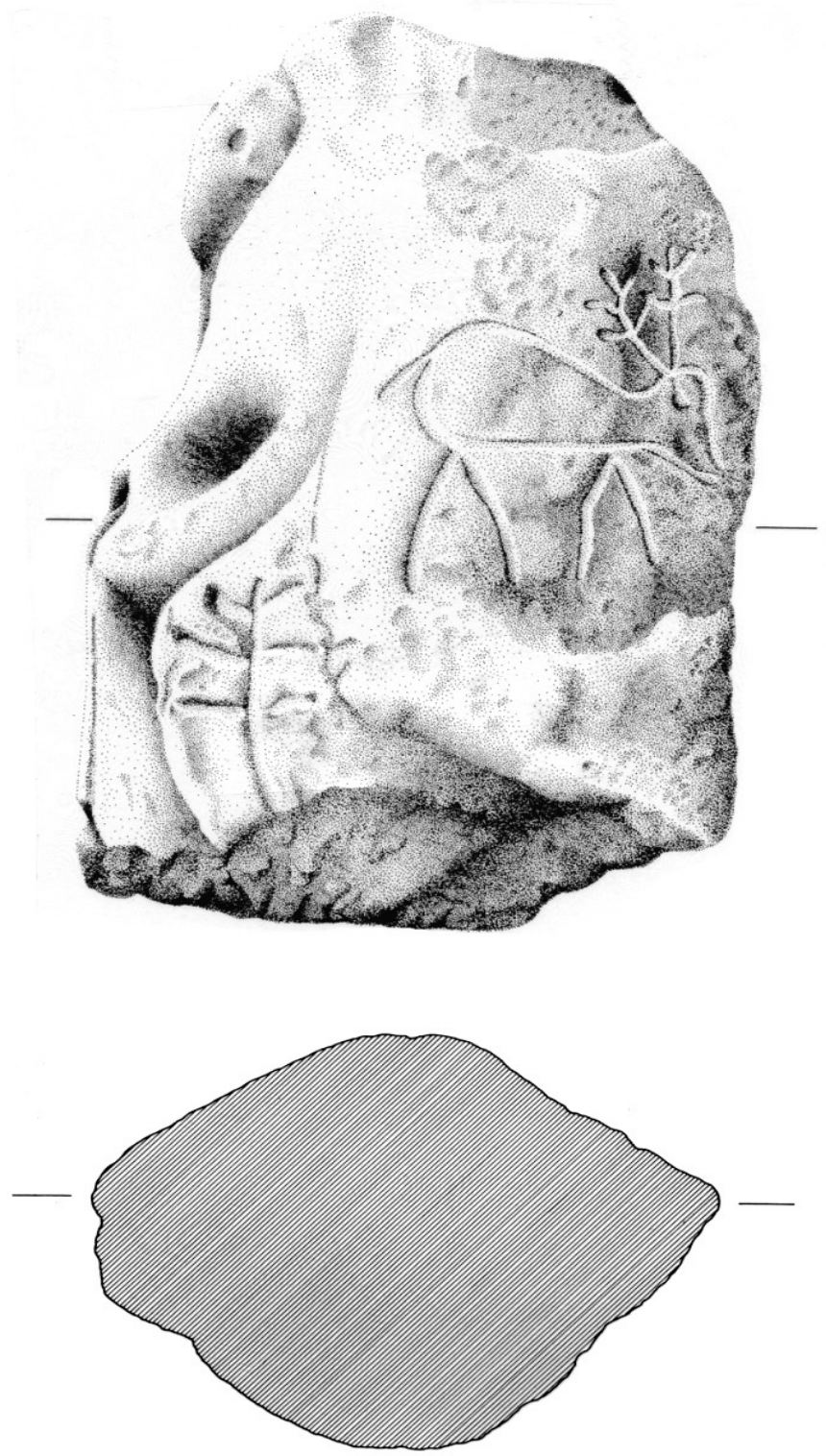

Estátua-sedente de Roriz. Vista lateral e secção (Des. Amélia Marques / Museu D. Diogo de Sousa) 
Est. V

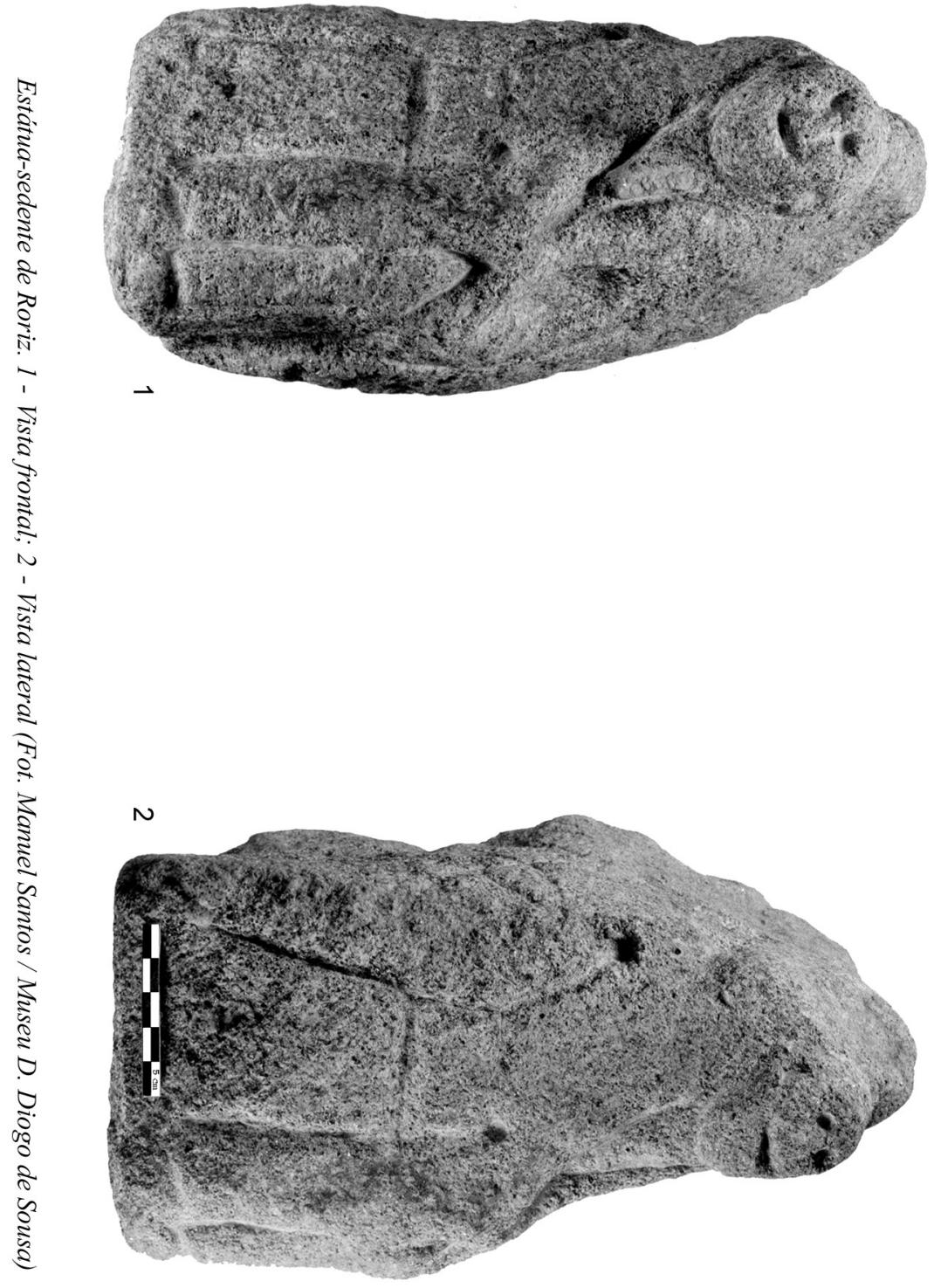


EST. VI

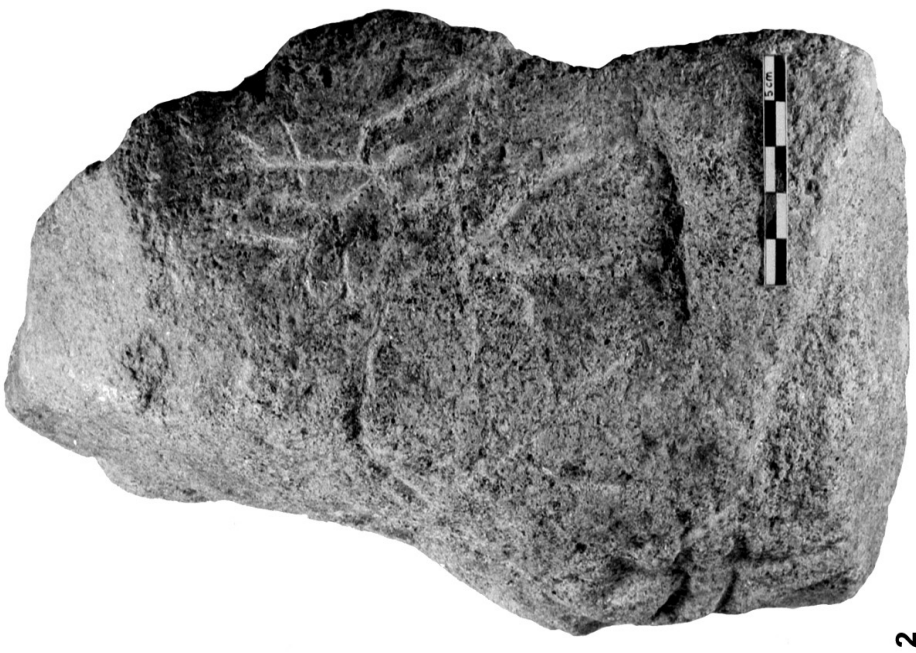

5
5
5
5

ป

8
8
8
0

จ

0

ปี

$\stackrel{2}{2}$

ริ

$N$

ई

ธิ

.

$\frac{2}{3}$

$\leftarrow$

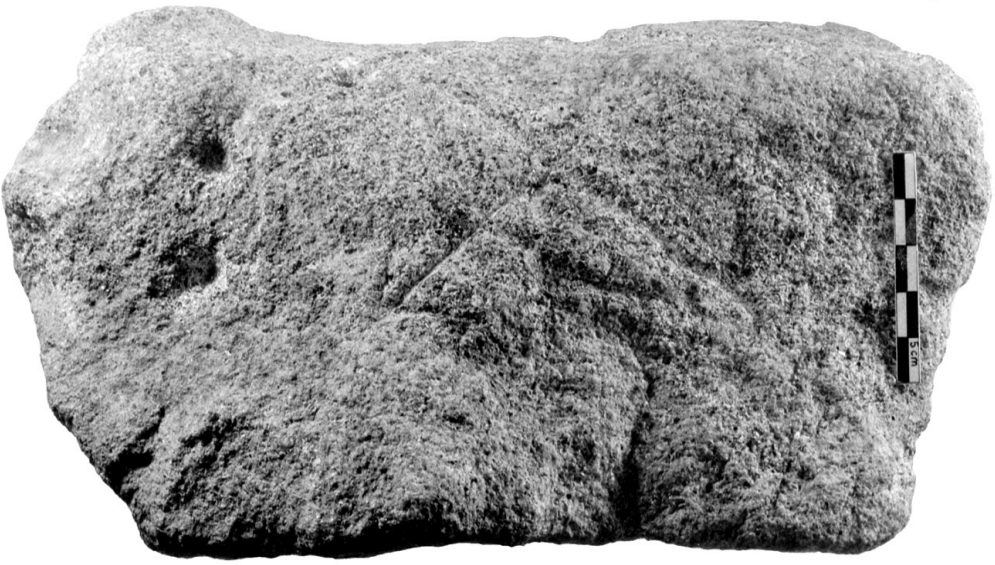




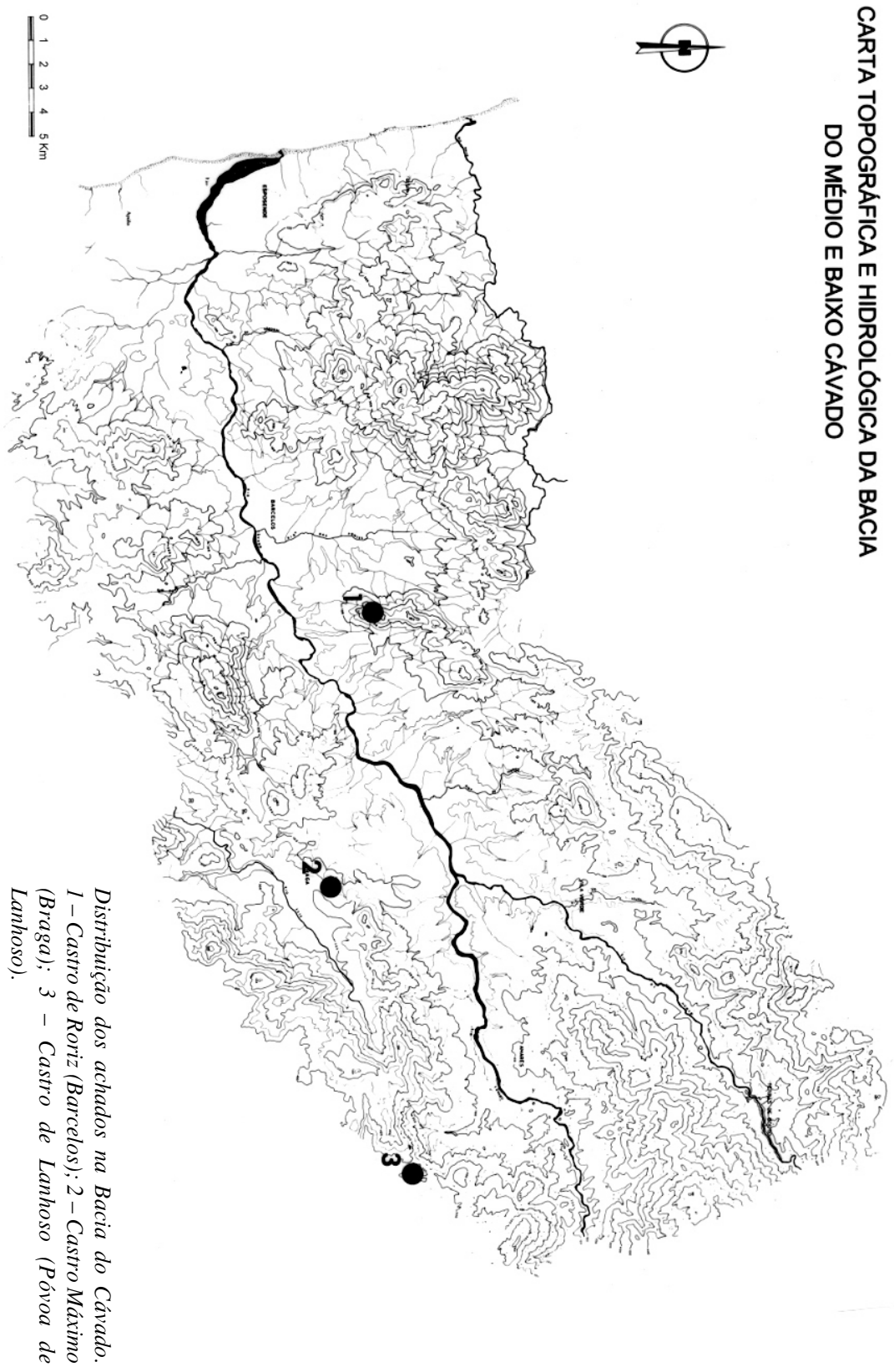




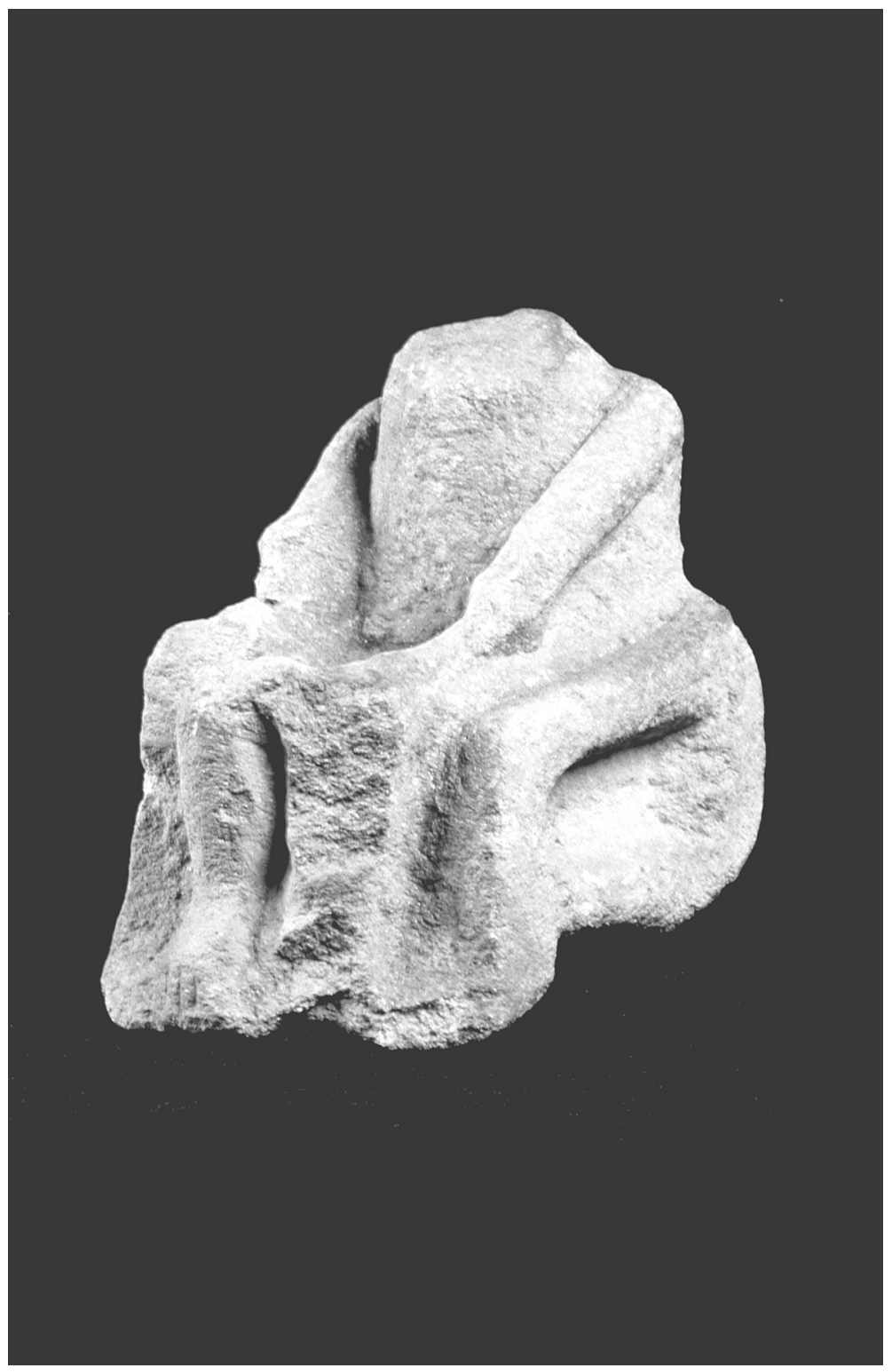

Estátua-sedente do Castro de Lanhoso (Barcelos) (Fot. Manuel Santos / Museu D. Diogo de Sousa) 
EST. IX

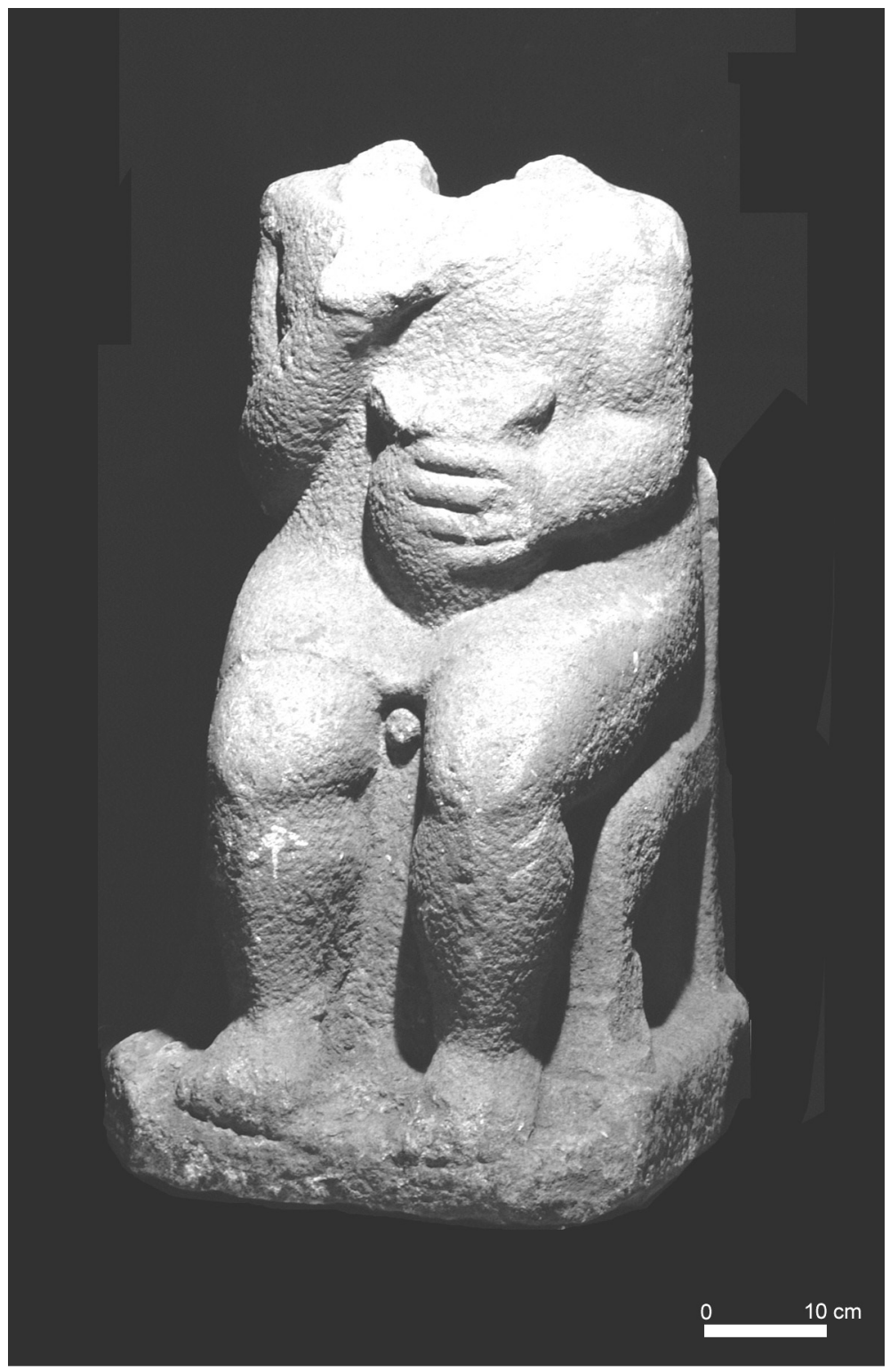

Estátua-sedente de Braga

(Fot. Manuel Santos / Museu D. Diogo de Sousa) 